Published in final edited form as:

Muscle Nerve. 2016 February ; 53(2): 214-221. doi:10.1002/mus.24899.

\title{
Respiratory Motor Function in Individuals with Centronuclear Myopathies
}

\author{
Barbara K. Smith, PhD, PT ${ }^{1}$, Markus S. Renno, MD², Meghan M. Green, BS ${ }^{3}$, Terry M. \\ Sexton, MSN, ARNP ${ }^{4}$, Lee Ann Lawson, MS, ARNP ${ }^{4}$, Anatole D. Martin, PhD, PT $^{1}$, Manuela \\ Corti, PhD, PT $^{4}$, and Barry J. Byrne, MD, PhD ${ }^{4}$ \\ ${ }^{1}$ Department of Physical Therapy, University of Florida, Gainesville, Florida, USA \\ ${ }^{2}$ Department of Pediatrics, Vanderbilt University, Nashville, Tennessee, USA \\ ${ }^{3}$ College of Medicine, University of Kentucky, Lexington, Kentucky, USA \\ ${ }^{4}$ Department of Pediatrics, University of Florida, Gainesville, Florida, USA
}

\section{Abstract}

Introduction-Individuals with X-linked myotubular myopathy (XLMTM) and other centronuclear myopathies (CNMs) frequently have profound respiratory insufficiency that requires support early in life. Still, few quantitative data exist to characterize respiratory motor function in CNM.

Methods-We evaluated the reliance upon mechanical ventilation (MV), ventilatory kinematics, unassisted tidal volumes, and maximal respiratory pressures in 14 individuals with CNMs, including 10 boys with XLMTM.

Results-Thirteen participants required full-time, invasive MV. Maximal inspiratory pressures were higher in subjects who breathed unsupported at least 1 hour per day than 24-hour MV users [33.7 (11.9-42.3) vs $\left.8.4(6.0-10.9) \mathrm{cm} \mathrm{H}_{2} \mathrm{O}, P<0.05\right]$. Years of MV dependence significantly correlated with MEP (r=-0.715, $P<0.01)$.

Discussion-Respiratory function in CNMs may be related to deconditioning from prolonged MV and/or differences in residual respiratory muscle strength. Results from this study may assist in evaluating severe respiratory insufficiency in neuromuscular clinical care and research.

\section{Keywords}

Centronuclear Myopathy; Myotubular Myopathy; Mechanical Ventilation; Respiratory Function; Clinical Trial Design

Corresponding author: Barbara K. Smith, PhD, PT, P.O. Box 100154, Gainesville, Florida 32610-0154, bksmith@phhp.ufl.edu. Conflicts of Interest:

None of the authors have conflicts of interest to report. 


\section{INTRODUCTION}

Centronuclear myopathies (CNMs) are a heterogeneous group of inherited muscle disorders characterized histologically by a predominance of immature, centrally-nucleated muscle fibers. Despite many similarities in the histological appearance of affected muscles, the clinical features of CNMs are diverse with regard to age and severity of onset, pattern of skeletal muscle weakness, and clinical manifestation. ${ }^{1}$ These features differ largely based on the underlying genetic mutation. ${ }^{2}$

The most common and severe CNM is X-linked myotubular myopathy (XLMTM), a disorder characterized by a deficiency of the phosphatase, myotubularin. Most affected newborns present with profound generalized weakness and typically require immediate mechanical ventilatory support. ${ }^{3}$ While mortality approaches $50 \%$ within the first 18 months of life, the disease is thought to be non-progressive in surviving children. ${ }^{4} \mathrm{~A}$ small minority of boys may achieve recovery of independent breathing, yet $>80 \%$ of children who survive their first year require chronic mechanical ventilation (MV). ${ }^{5,6}$

The presentation of autosomally-derived CNMs is more variable than that of XLMTM. Autosomal dominant disorders include mutations of the genes that encode dynamin-2 (DNM2) or the ryanodine receptor (RYR1). Respiratory involvement in DNM2 myopathy may include a weak cough and restrictive lung disease in severe cases, however external ventilator use is infrequent. $R Y R l$ myopathy is characterized by a higher incidence of earlyonset generalized weakness, bulbar weakness, and respiratory dysfunction. Autosomal recessive disorders include mutations in the amphyphysin 2 (BIN1) or titin (TTN) gene sequences. Early-onset BIN1 myopathies result in a higher prevalence of respiratory insufficiency and requirement for external support. The $T T N$ mutation was recently identified and appears to manifest a variable weakness pattern and progression of respiratory symptoms. ${ }^{7}$ It is estimated that approximately $30 \%$ of children with histological features of CNM carry a mutation that has not yet been identified. ${ }^{1,8}$

There is a high prevalence of respiratory muscle involvement in CNMs, and respiratory complications are a primary source of morbidity and mortality. ${ }^{4}$ Although respiratory muscle insufficiency is a common attribute of this diverse group of disorders, the patterns of respiratory muscle involvement and functional limitations have not been well defined. As new therapies become available in the future, it is crucial to prospectively evaluate the mode, extent, and progression of respiratory motor dysfunction in CNMs. A greater understanding of the baseline respiratory function could enhance clinical decision-making and facilitate comparisons of function in future therapeutic studies. Therefore, the purpose of this study is to characterize respiratory motor function in patients with CNMs.

\section{MATERIALS AND METHODS}

\section{Design}

This study was approved by the University of Florida Institutional Review Board (IRB). Our evaluation consisted of a history and physical examination, followed by a single session of 
respiratory muscle testing of the breathing pattern with and without mechanical ventilation (MV) support, peak voluntary cough flow, and maximal respiratory pressures.

\section{Participants}

Individuals with a diagnosis of a CNM between the ages of 1 and 65 years were eligible to participate. Exclusionary criteria included an active fever, presence of resting cardiac arrhythmias, and changes in medications within the last 7 days. All participants were attendees at a patient and family conference for CNM and XLMTM. The IRB approved recruitment via advertisements in the pre-conference literature. Participants 18 years and older provided their own informed consent. Assent was obtained from participants between ages 8 and 17 years before any study procedures were performed.

In an interview with participants and their families, an extensive history was obtained, including the onset and course of ventilatory insufficiency, medical comorbidities and complications, time to tracheostomy, daily requirement of assisted ventilation, and use of other respiratory adaptive aids. Families provided contact information to local providers for the collection of relevant medical records and genetic tests.

\section{Respiratory testing}

Prior to the respiratory test session, participants with tracheostomies were suctioned. The evaluation was conducted while subjects were seated as upright as possible. Participants were monitored with 3-lead electrocardiography, capnography, and pulse oximetry throughout the testing. The tracheostomy cuff was inflated when present, and a respiratory analyzer and combined airflow/ $\mathrm{CO}_{2}$ sensor $\left(\mathrm{CO}_{2} \mathrm{SMO}\right.$ Plus and Capnostat, Respironics, USA) captured inspiratory and expiratory time, flow, volume, and pressure at a rate of 100 Hz. A data acquisition system (PowerLab 16/30, ADInstruments, USA) was used to record the electrocardiogram $(1000 \mathrm{~Hz})$ and the chest and abdominal respiratory movements (RespiTrace, CareFusion, USA, recorded at $200 \mathrm{~Hz}$ ). The piezoelectric respiratory bands were placed on the chest between the nipple line and the underarms, and on the abdomen just above the navel. Participants acclimated to the sensors and testing environment for a minimum of 5 minutes before recordings began. All data were recorded on a passwordprotected laptop computer.

Respiratory Measurements with $\mathrm{MV}$ - The flow/ $\mathrm{CO}_{2}$ sensor was placed in series with the ventilator circuit. The ventilator settings, breathing parameters, and respiratory kinematics were recorded on full support for a minimum of 15 minutes, after steady state was verified (determined by stable tidal volumes or plethysmography tracings). The participants' abdominal and chest movements were assessed for synchrony during full MV support and were categorized as synchronous, partially asynchronous, or paradoxical.

Respiratory Pattern without MV-The breathing pattern and respiratory movements were also measured during periods with the ventilator disconnected. Participants were returned to their baseline ventilator settings once they reached any of the pre-defined stopping criteria, which included excessive increases in heart rate or respiratory rate, drop in oxygen saturation, emergence of arrhythmias, elevated end-tidal $\mathrm{CO}_{2}$, or general distress as 
perceived by the participant, parent or a member of the study team. If participants remained stable at 10 minutes of unsupported, steady state breathing, they were returned to MV. Respiratory timing was determined using the synchronized waveforms from the airflow, and qualitative respiratory movements were again categorized according to synchrony, or partial or complete asynchrony of chest and abdominal movement.

Voluntary Cough-After a minimum 10-minute rest on full MV support, participants aged 7 and older were instructed to attempt to voluntarily cough while breathing spontaneously without MV. Instructions were provided to "pretend you have something stuck in your chest that you have to get out." Three voluntary cough attempts were recorded on full MV, followed by 3-5 trials while disconnected from the ventilator. Between the unassisted attempts, participants rested for at least 2 minutes on full MV. The cough attempt with the highest peak flow was recorded. Participants younger than 7 years did not complete the voluntary cough maneuver, although spontaneous coughs during the recording session were annotated. If, during the cough effort, the unassisted peak expiratory flow changed $<5 \%$ from the average of the preceding 3 control breaths, the cough was considered nonfunctional.

Maximal Inspiratory Pressure-Maximal inspiratory pressure (MIP) was the most negative pressure a participant could voluntarily generate. For the ventilator-dependent participants, we employed the 20 -second inspiratory occlusion technique first described by Truwit and Marini for use in ICU patients ${ }^{9}$ and later validated in children with acute ventilator dependence. ${ }^{10}$ Briefly, participants were disconnected from the ventilator circuit. A recording manometer was placed in series with a one-way valve that blocked inspiration, and these were directly attached to the tracheostomy tube. Participants were encouraged to attempt to exhale and inhale as forcefully as possible for 20 seconds. Peak inspiratory pressure was typically achieved between 15-20 seconds occlusion. Three efforts were performed and separated by 3-5 minutes rest on full MV. The best effort was reported.

Participants who were not ventilator-dependent followed ATS-ERS guidelines for maximal inspiratory pressure from residual volume. ${ }^{11}$ Strong encouragement was provided to generate a maximal effort. Three trials within $10 \%$ variation were attempted, and the best effort was reported.

Maximal Expiratory Pressure-Maximal expiratory pressure (MEP) was the highest positive pressure the participant could voluntarily generate. As with the MIP technique above, this was assessed for ventilator-dependent participants with a 20-second period of occlusion, this time with the one-way valve preventing expiratory flow. Participants were disconnected from the ventilator, and the pressure transducer and one-way valve were attached directly to the tracheostomy tube. Participants were instructed to inhale and exhale forcefully for up to 20 seconds. During this time, lung volumes and respiratory efforts progressively increased, and peak expiratory pressures were again typically reached between 15-20 seconds occlusion. Three efforts were recorded with 3-5 minute rests on the usual ventilator settings between trials. The effort with the most positive pressure was reported. 
Participants who were not ventilator dependent completed standard MEP maneuvers according to ATS-ERS guidelines. ${ }^{11}$ While using a mouthpiece and nose clip, participants inhaled to total lung capacity, followed by a 3-second maximal expiratory effort. Testers provided strong verbal encouragement during the maneuver. Three trials were obtained within a $20 \%$ variation and separated by 3 minutes of rest. The best effort was reported.

\section{Data analysis}

Demographic and breathing pattern descriptive statistics were summarized as mean and standard deviation, and the change in breathing pattern during unassisted ventilation was compared using a $t$-test (with Bonferonni correction for multiple analyses).

Maximal respiratory pressures were compared to an age-appropriate reference. ${ }^{12-14} \mathrm{We}$ specifically investigated the following relationships: (1) asynchronies of respiratory movements and unassisted tidal volume, (2) differences in respiratory motor function stratified by the daily time spent breathing independently, and (3) relationship between duration of daytime invasive MV dependence and maximal respiratory pressures. Sub-group comparisons of time of independent breathing and synchrony did not meet the assumption for normality. These comparisons were described with median (IQR) and evaluated with either a Mann-Whitney or Kruskal-Wallis test. Distinctions in off-ventilator breathing and paradoxical chest movements were evaluated with chi-square tests. Pearson correlation was used to describe the relationship between the duration of MV dependence and maximal respiratory pressures. Significance was set at $P<0.05$.

\section{RESULTS}

Fourteen individuals with CNMs consented to participate in the study. Their demographics, genetic information, and respiratory history are summarized in Table 1. Ten participants had XLMTM confirmed by sequence analysis. The remaining 4 received diagnoses of confirmed DNM2 myopathy ( $\mathrm{n}=1)$, RYR1 myopathy $(\mathrm{n}=1)$, CNM with unspecified mutation $(\mathrm{n}=1)$, and CNM with unspecified mutation - presumed XLMTM $(n=1)$. Participant ages ranged between 19 months and 22 years. The majority of participants had a history of kyphoscoliosis $(n=11)$. One child had a diagnosis of nonspecific chronic lung disease in the medical history provided by the primary care provider.

\section{Ventilator use}

Notably, 13 of the 14 participants used invasive MV during most or all of the daytime hours. The remaining participant was ambulatory and required non-invasive MV only during sleep. Most participants experienced ventilatory failure and tracheostomy at a young age, and 9 required full-time MV since birth. About half ( $\mathrm{n}=7$ ) still required 24-hour MV to support breathing, while the others $(n=6)$ tolerated 1 or more hours off the ventilator on a routine basis. Five participants used an uncuffed tracheostomy tube, and the resulting large air leak limited our ability to accurately measure volumes during full MV support. A minimal thoracic phase lag was observed in 3 patients with severe kyphoscoliosis during the resting MV condition. 


\section{Unassisted breathing pattern}

All of the MV-dependent participants were able to breathe independently for at least a few minutes at a time. Due to time limitations, we only recorded up to 10 minutes of unassisted breathing in each participant. While breathing spontaneously without the ventilator, the air leak was $<20 \%$ in all 13 of the participants who used daytime MV, and $<10 \%$ in 9 participants [\% air leak $=$ (inspiratory volume - expiratory volume) $/$ inspiratory volume]. Table 2 summarizes the observed changes in breathing parameters on removal of MV support for the 8 patients without a cuff leak while on MV. When compared to full MV support, the unassisted breathing pattern consisted of a significantly increased respiratory rate and sharply lower tidal volumes for most patients. In addition to the rapid, shallow breathing pattern, we observed thoracoabdominal asynchrony in some participants when MV support was removed. Figure 1 illustrates that unassisted tidal volumes were generally lower in those who demonstrated paradoxical chest and abdominal movements, yet this was not statistically significant (Kruskal Wallis, $P=0.15$ ). The proportion of participants with paradoxical movements was not higher in full-time participants $\left(X^{2}=0.66\right)$ or in those who were returned to MV before the maximum off-vent time $\left(\mathrm{X}^{2}=0.37\right)$. No participants had to be returned to the ventilator due to arrhythmias; the most common stopping factors were an elevated heart rate or an increase in end-tidal $\mathrm{CO}_{2}$ (from $29.2 \pm 4.1$ to $33.0 \pm 4.2 \mathrm{~mm} \mathrm{Hg}$, $P<0.05)$.

\section{Respiratory pressures and cough function}

Maximal inspiratory pressures were below the age- and gender-predicted values in all patients (18.8 $\pm 14.2 \mathrm{~cm} \mathrm{H}_{2} \mathrm{O}, 23.6 \pm 18.9 \%$ of predicted value). Likewise, maximal expiratory pressures were also well below reference values $\left(14.4 \pm 10.2 \mathrm{~cm} \mathrm{H}_{2} \mathrm{O}, 17.0 \pm 13.2 \%\right.$ of predicted value). Figure 2 illustrates the maximal respiratory pressures of participants as a function of their reported tolerance to independent breathing. The maximal inspiratory pressure was significantly greater among participants who breathed independently for at least 1 hour on a routine basis [24 hours MV: $8.4(6.0-10.9) \mathrm{cm} \mathrm{H}_{2} \mathrm{O} ;<23$ hours MV: 33.7 (11.9-42.3) $\mathrm{cm} \mathrm{H}_{2} \mathrm{O}$, Mann-Whitney, $\left.P<0.05\right]$. Conversely, the maximal expiratory pressure did not differ based upon the daily time of unassisted breathing [24 hours MV: 6.9 (6.013.0) $\mathrm{cm} \mathrm{H}_{2} \mathrm{O}$; $<23$ hours MV: $18.4(9.2-31.1) \mathrm{cm} \mathrm{H}_{2} \mathrm{O}$, Mann-Whitney, $\left.P=0.10\right]$. Figure 3 shows the relationships between the years of MV dependence and the age-predicted maximal respiratory pressures. Among the 13 participants who used daytime invasive MV, duration of MV dependence did not significantly correlate with age-predicted MIP ( $\mathrm{r}=$ $-0.482, P=0.10)$. However, the duration of MV dependence was significantly related to age-predicted MEP $(\mathrm{r}=-0.715, P<0.01)$. Only 2 participants were able to demonstrate a functional voluntary cough. Peak cough flow was $130.2 \mathrm{~L} / \mathrm{min}$ for the participant who used non-invasive MV only during sleep, and the participant who underwent tracheostomy at age 16 generated a $52.3 \mathrm{~L} / \mathrm{min}$ peak cough flow.

\section{DISCUSSION}

This observational study provides novel information on the respiratory function of patients with CNM and the potential influences of growth, maturation, disease progression, and secondary consequences of the disease. Previous observational studies of CNMs have not 
typically described respiratory motor function beyond a daily requirement for MV. $2,4,15,16$

In contrast, this evaluation of respiratory motor function in CNM included the following quantitative measures: unassisted breathing pattern, maximal respiratory pressures, generation of voluntary cough, and synchrony of thoracoabdominal movements. Respiratory muscle function tests have been implemented safely in other MV-dependent neuromuscular diseases, ${ }^{17-19}$ and all of the participants similarly tolerated the procedures without complication. While nearly all participants required full-time MV, there was considerable variability in respiratory muscle function. This variability in respiratory muscle capacity should be considered in experimental designs.

We found that participants who routinely spent at least 1 hour per day breathing independently had a significantly higher MIP than participants who spent less time off the ventilator. However, the number of years of full-time MV dependence did not significantly predict MIP. Based upon these data, we hypothesize that a regular respiratory challenge could preserve residual inspiratory muscle function. It is known that, in the absence of neuromuscular disease, MV elicits rapid plasticity of the respiratory motor system. These changes include a rapid decrease in inspiratory drive ${ }^{20}$ and ventilator-induced diaphragm dysfunction (VIDD), which is characterized by muscle fiber atrophy and contractile dysfunction. ${ }^{21}$ While oxidative stress and systemic inflammation assume major roles in acute respiratory failure and VIDD, inactivity perpetuates the sequelae. In other clinical situations, diaphragm activity, whether through reduced MV settings or specific respiratory exercises, appears to better preserve inspiratory motor function. ${ }^{22-25} \mathrm{It}$ is not known whether physiological principles of VIDD and the preservation of inspiratory function with an activity prescription are analogous in ventilator-dependent CNM. Alternatively, genotype-phenotype associations have been reported for some genetic mutations. ${ }^{1,2}$ In other words, tolerance to unsupported breathing could have been influenced independently by a genetic mutation associated with a milder clinical presentation. Either of these scenarios is plausible. In either case, we recommend that medically stable patients maintain their capacity for breathing when possible to minimize deconditioning effects of continuous highlevel MV. Participants generally had a rapid, shallow unassisted breathing pattern and a low capacity for prolonged, unassisted breathing. However, many could sustain their minute ventilation voluntarily with a much-reduced programmed rate and pressure support (observations on $\mathrm{n}=13$ ). We suggest an individualized exercise prescription to encompass short sessions of progressively reduced MV support with close physiological monitoring to prevent fatigue and hypoventilation.

Although routine periods of unassisted breathing were associated with preservation of MIP, we did not find this to be the case with MEP. MEP was profoundly decreased from age- and gender-predicted reference values, and in other neuromuscular diseases it significantly correlates with cough function. ${ }^{26}$ Only 2 participants were able to generate a functional cough. Notably, these participants were the oldest in the study and had the highest maximal respiratory pressures of the sample. This observation could be related to their CNM subtype; none of the confirmed XLMTM participants coughed voluntarily (RYR1: $n=1$, and unspecified CNM/presumed MTM: $\mathrm{n}=1$ ). Another distinction is that neither participant required daytime invasive ventilation during early infancy. While reflexive cough can be stimulated in neonates, the airway defenses continue to mature for several months after 
birth. ${ }^{27}$ Hypercapnia and hypoxic events in early infancy alter the maturation of respiratory control, ${ }^{28,29}$ but it is not known whether respiratory failure and invasive MV in early infancy also influences maturation of defensive reflexes. The peak cough flows of the 2 participants were well below the $160 \mathrm{~L} / \mathrm{min}$ threshold for effectiveness and were associated with chest infections in other neuromuscular diseases. ${ }^{30,31}$ Both participants utilized assisted coughing strategies as part of their routine pulmonary hygiene. The small number of participants who could voluntarily cough necessitates further study in a larger sample.

Participants with paradoxical respiratory movements tended also to generate smaller normalized tidal volumes, but this was not statistically significant. We acknowledge that not all of the subjects were tested until failure; 7 participants did not reach the point of failure after 10 minutes of unassisted breathing. While the prevalence of paradoxical respiratory movements was not different in participants who were tested to failure, paradoxical thoracoabdominal motion results in a higher work of breathing that can limit a patient's ability to breathe independently over the longer term. ${ }^{32}$ Asynchronous movements can be affected by respiratory compliance, musculoskeletal deformities or contractures, or asymmetries in the relative strength of the intercostal muscles and diaphragm. These secondary factors may deteriorate with longitudinal growth and prolonged immobility.

Although the ventilator-dependent CNMs have traditionally been considered nonprogressive, additional respiratory muscle capacity may be lost from ongoing disuse atrophy and increased chest wall stiffness related to MV, immobility, postural derangements, and longitudinal growth. In other words, respiratory muscle involvement in CNMs may not be a static state driven exclusively by the genetic mutation, and function may continue to change over time. Evidence of this can be seen in the significant relationship between the years of MV dependence and MEP.

This study had several limitations worth noting. First, statistical power was likely limited by the sample size. However, this sample represents a large sample of the living patients in the US with CNM. ${ }^{2}$ Further, to our knowledge, this is the largest quantitative study of respiratory motor function in this rare disease population. This report is additionally limited by its cross-sectional design. Evaluation of the longitudinal changes in respiratory motor function in the CNMs would lend additional strength to the study. We also understand that biases can be introduced when using a sample of convenience. By enrolling participants at a patient and family conference, we limited our sample to participants who were medically stable and whose families either had the means to travel long distances to such an event or resided near the test site. Finally, even though most participants had profound MV dependence, it may be interpreted that the sample generally included those on the milder end of the disease spectrum, since many infants with CNMs succumb to respiratory failure in infancy, and others may have been too sick to travel. Therefore, the data could suggest a somewhat different respiratory motor function than the overall population of patients with CNM. Despite these limitations, it is our hope that these data will assist clinicians and researchers in their efforts to systematically evaluate respiratory motor function.

Looking ahead, investigators should consider the heterogeneity of respiratory motor function in MV-dependent participants in both clinical management and the design of clinical trials. 
It appears that some dimensions of respiratory motor function may continue to decline over time, which could be mutation-related due to effects of MV on respiratory control or result from secondary effects of growth and immobility. However, inspiratory function in particular could potentially be preserved with routine activity in the form of short periods of reduced support. Additional longitudinal examination of respiratory motor function is indicated to further investigate influences of genetic factors, growth, MV, and spontaneous breathing activity on year-to-year function.

\section{Acknowledgments}

Financial Disclosures:

BKS was supported by National Institutes of Health (K12 HD055929). MSR was supported by the University of Florida Department of Pediatrics.

\section{ABBREVIATIONS}

$\begin{array}{ll}\text { BIN1 } & \text { Amphyphysin 2 } \\ \text { CNM } & \text { Centronuclear Myopathy } \\ \text { DNM2 } & \text { Dynamin-2 } \\ \text { IQR } & \text { Interquartile Range } \\ \text { IRB } & \text { Institutional Review Board } \\ \text { MEP } & \text { Maximal Expiratory Pressure } \\ \text { MIP } & \text { Maximal Inspiratory Pressure } \\ \text { MV } & \text { Mechanical Ventilation } \\ \text { RYR1 } & \text { Ryanodine Receptor } \\ \text { TTN } & \text { Titin } \\ \text { VIDD } & \text { Ventilator-induced diaphragm dysfunction } \\ \text { XLMTM } & \text { X-Linked Myotubular Myopathy }\end{array}$

\section{REFERENCES}

1. Romero NB. Centronuclear myopathies: a widening concept. Neuromuscul Disord. 2010; 20(4): 223-228. [PubMed: 20181480]

2. Jungbluth, H.; Wallgren-Pettersson, C.; Laporte, JF.; Centronuclear myopathy, C. Neuromuscul Disord; 198th ENMC International Workshop: 7th Workshop on Centronuclear (Myotubular) myopathies; 31st May - 2nd June 2013; Naarden, The Netherlands. 2013. p. 1033-1043.

3. Buj-Bello A, Biancalana V, Moutou C, Laporte J, Mandel JL. Identification of novel mutations in the MTM1 gene causing severe and mild forms of X-linked myotubular myopathy. Hum Mutat. 1999; 14(4):320-325. [PubMed: 10502779]

4. McEntagart M, Parsons G, Buj-Bello A, Biancalana V, Fenton I, Little M, Krawczak M, Thomas N, Herman G, Clarke A, Wallgren-Pettersson C. Genotype-phenotype correlations in X-linked myotubular myopathy. Neuromuscul Disord. 2002; 12(10):939-946. [PubMed: 12467749] 
5. Herman GE, Finegold M, Zhao W, de Gouyon B, Metzenberg A. Medical complications in longterm survivors with X-linked myotubular myopathy. J Pediatr. 1999; 134(2):206-214. [PubMed: 9931531]

6. Laporte J, Biancalana V, Tanner SM, Kress W, Schneider V, Wallgren-Pettersson C, Herger F, BujBello A, Blondeau F, Liechti-Gallati S, Mandel JL. MTM1 mutations in X-linked myotubular myopathy. Hum Mutat. 2000; 15(5):393-409. [PubMed: 10790201]

7. Ceyhan-Birsoy O, Agrawal PB, Hidalgo C, Schmitz-Abe K, Dechene ET, Swanson LC, Soemedi R, Vasli N, Iannaccone ST, Shieh PB, Shur N, Dennison JM, Lawlor MW, Laporte J, Markianos K, Fairbrother WG, Granzier H, Beggs AH. Recessive truncating titin gene, TTN, mutations presenting as centronuclear myopathy. Neurology. 2013

8. Amburgey K, McNamara N, Bennett LR, McCormick ME, Acsadi G, Dowling JJ. Prevalence of congenital myopathies in a representative pediatric united states population. Ann Neurol. 2011; 70(4):662-665. [PubMed: 22028225]

9. Truwit JD, Marini JJ. Validation of a technique to assess maximal inspiratory pressure in poorly cooperative patients. Chest. 1992; 102(4):1216-1219. [PubMed: 1395771]

10. Harikumar G, Moxham J, Greenough A, Rafferty GF. Measurement of maximal inspiratory pressure in ventilated children. Pediatr Pulmonol. 2008; 43(11):1085-1091. [PubMed: 18846557]

11. ATS/ERS Statement on respiratory muscle testing. Am J Respir Crit Care Med. 2002; 166(4):518624. [PubMed: 12186831]

12. Shardonofsky FR, Perez-Chada D, Carmuega E, Milic-Emili J. Airway pressures during crying in healthy infants. Pediatr Pulmonol. 1989; 6(1):14-18. [PubMed: 2704577]

13. Domenech-Clar R, Lopez-Andreu JA, Compte-Torrero L, De Diego-Damia A, Macian-Gisbert V, Perpina-Tordera M, Roques-Serradilla JM. Maximal static respiratory pressures in children and adolescents. Pediatr Pulmonol. 2003; 35(2):126-132. [PubMed: 12526074]

14. Evans JA, Whitelaw WA. The assessment of maximal respiratory mouth pressures in adults. Respir Care. 2009; 54(10):1348-1359. [PubMed: 19796415]

15. Herman GE, Kopacz K, Zhao W, Mills PL, Metzenberg A, Das S. Characterization of mutations in fifty North American patients with X-linked myotubular myopathy. Hum Mutat. 2002; 19(2):114121. [PubMed: 11793470]

16. Romero NB, Bitoun M. Centronuclear myopathies. Semin Pediatr Neurol. 2011; 18(4):250-256. [PubMed: 22172420]

17. Smith BK, Collins SW, Conlon TJ, Mah CS, Lawson LA, Martin AD, Fuller DD, Cleaver BD, Clement N, Phillips D, Islam S, Dobjia N, Byrne BJ. Phase I/II Trial of Adeno-Associated VirusMediated Alpha-Glucosidase Gene Therapy to the Diaphragm for Chronic Respiratory Failure in Pompe Disease: Initial Safety and Ventilatory Outcomes. Hum Gene Ther. 2013; 24(6):630-640. [PubMed: 23570273]

18. Beck J, Weinberg J, Hamnegard CH, Spahija J, Olofson J, Grimby G, Sinderby C. Diaphragmatic function in advanced Duchenne muscular dystrophy. Neuromuscul Disord. 2006; 16(3):161-167. [PubMed: 16488607]

19. Hahn A, Duisberg B, Neubauer BA, Stephani U, Rideau Y. Noninvasive determination of the tension-time index in Duchenne muscular dystrophy. Am J Phys Med Rehabil. 2009; 88(4):322 327. [PubMed: 19190489]

20. Sharshar T, Ross ET, Hopkinson NS, Porcher R, Nickol AH, Jonville S, Dayer MJ, Hart N, Moxham J, Lofaso F, Polkey MI. Depression of diaphragm motor cortex excitability during mechanical ventilation. J Appl Physiol. 2004; 97(1):3-10. [PubMed: 15020575]

21. Levine S, Nguyen T, Taylor N, Friscia ME, Budak MT, Rothenberg P, Zhu J, Sachdeva R, Sonnad S, Kaiser LR, Rubinstein NA, Powers SK, Shrager JB. Rapid disuse atrophy of diaphragm fibers in mechanically ventilated humans. N Engl J Med. 2008; 358(13):1327-1335. [PubMed: 18367735]

22. Martin AD, Smith BK, Davenport P, Harman E, Gonzalez-Rothi RJ, Baz M, Layon AJ, Banner M, Caruso LJ, Deoghare H, Huang TT, Gabrielli A. Inspiratory muscle strength training improves weaning outcome in failure to wean patients: a randomized trial. Crit Care. 2011; 15(2):R84. [PubMed: 21385346] 
23. Martin AD, Joseph AM, Beaver TM, Smith BK, Martin TD, Berg K, Hess PJ, Deoghare HV, Leeuwenburgh $\mathrm{C}$. Effect of intermittent phrenic nerve stimulation during cardiothoracic surgery on mitochondrial respiration in the human diaphragm. Crit Care Med. 2014; 42(2):e152-e156. [PubMed: 24126442]

24. Sassoon CS, Zhu E, Caiozzo VJ. Assist-control mechanical ventilation attenuates ventilatorinduced diaphragmatic dysfunction. Am J Respir Crit Care Med. 2004; 170(6):626-632. [PubMed: 15201132]

25. Futier E, Constantin JM, Combaret L, Mosoni L, Roszyk L, Sapin V, Attaix D, Jung B, Jaber S, Bazin JE. Pressure support ventilation attenuates ventilator-induced protein modifications in the diaphragm. Crit Care. 2008; 12(5):R116. [PubMed: 18786263]

26. Park JH, Kang SW, Lee SC, Choi WA, Kim DH. How respiratory muscle strength correlates with cough capacity in patients with respiratory muscle weakness. Yonsei Med J. 2010; 51(3):392-397. [PubMed: 20376892]

27. Chang AB, Widdicombe JG. Cough throughout life: children, adults and the senile. Pulm Pharmacol Ther. 2007; 20(4):371-382. [PubMed: 17118685]

28. Carroll JL, Agarwal A. Development of ventilatory control in infants. Paediatr Respir Rev. 2010; 11(4):199-207. [PubMed: 21109177]

29. Bavis RW, Mitchell GS. Long-term effects of the perinatal environment on respiratory control. J Appl Physiol (1985). 2008; 104(4):1220-1229. [PubMed: 18187608]

30. Bach JR, Saporito LR. Criteria for extubation and tracheostomy tube removal for patients with ventilatory failure. A different approach to weaning. Chest. 1996; 110(6):1566-1571. [PubMed: 8989078]

31. Dohna-Schwake C, Ragette R, Teschler H, Voit T, Mellies U. Predictors of severe chest infections in pediatric neuromuscular disorders. Neuromuscul Disord. 2006; 16(5):325-328. [PubMed: 16621559]

32. Perez A, Mulot R, Vardon G, Barois A, Gallego J. Thoracoabdominal pattern of breathing in neuromuscular disorders. Chest. 1996; 110(2):454-461. [PubMed: 8697851] 


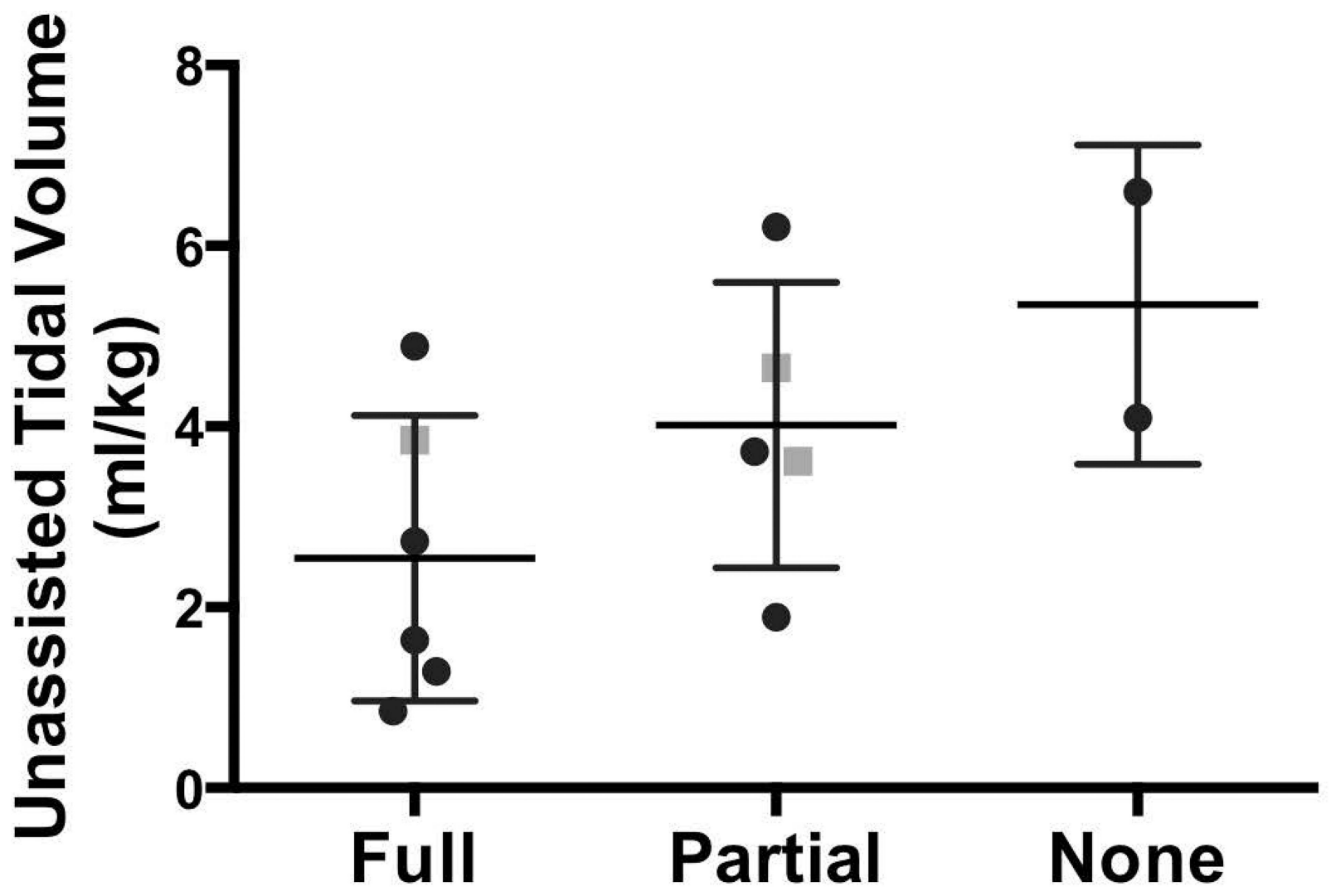

\section{Presence of Thoracic Paradoxical Motion}

Figure 1.

Unassisted tidal volumes of ventilator-dependent participants with CNM. Thoracoabdominal movements were classified as fully synchronous, partially asynchronous, or fully asynchronous (paradoxical) during unassisted ventilation. There was a trend for participants with greater thoracoabdominal synchrony to generate smaller tidal volumes, but this difference was not statistically significant $(P=0.15)$. Black circles represent participants with XLMTM, while grey squares represent participants with other CNMs. 

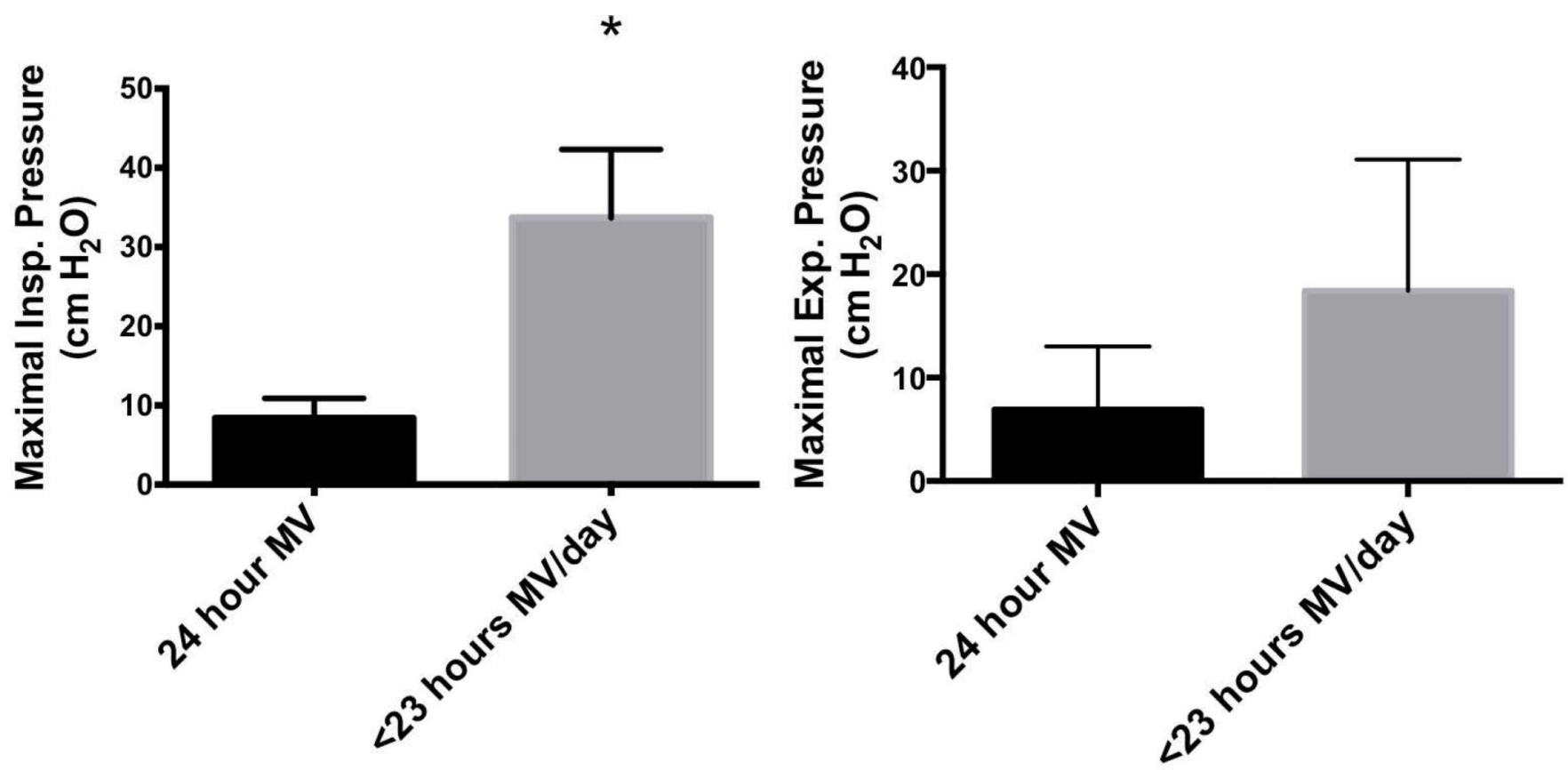

A

B

Figure 2.

Maximal respiratory pressures in ventilator-dependent participants with CNM. Participants were grouped according to their routine practice of independent breathing. (A) Maximal inspiratory pressure was significantly higher in participants who routinely breathed without MV for at least 1 hour daily $(P<0.05)$. (B) Maximal expiratory pressure also trended higher among participants with more routine independent breathing, but this difference was not statistically significant $(P=0.10)$. 

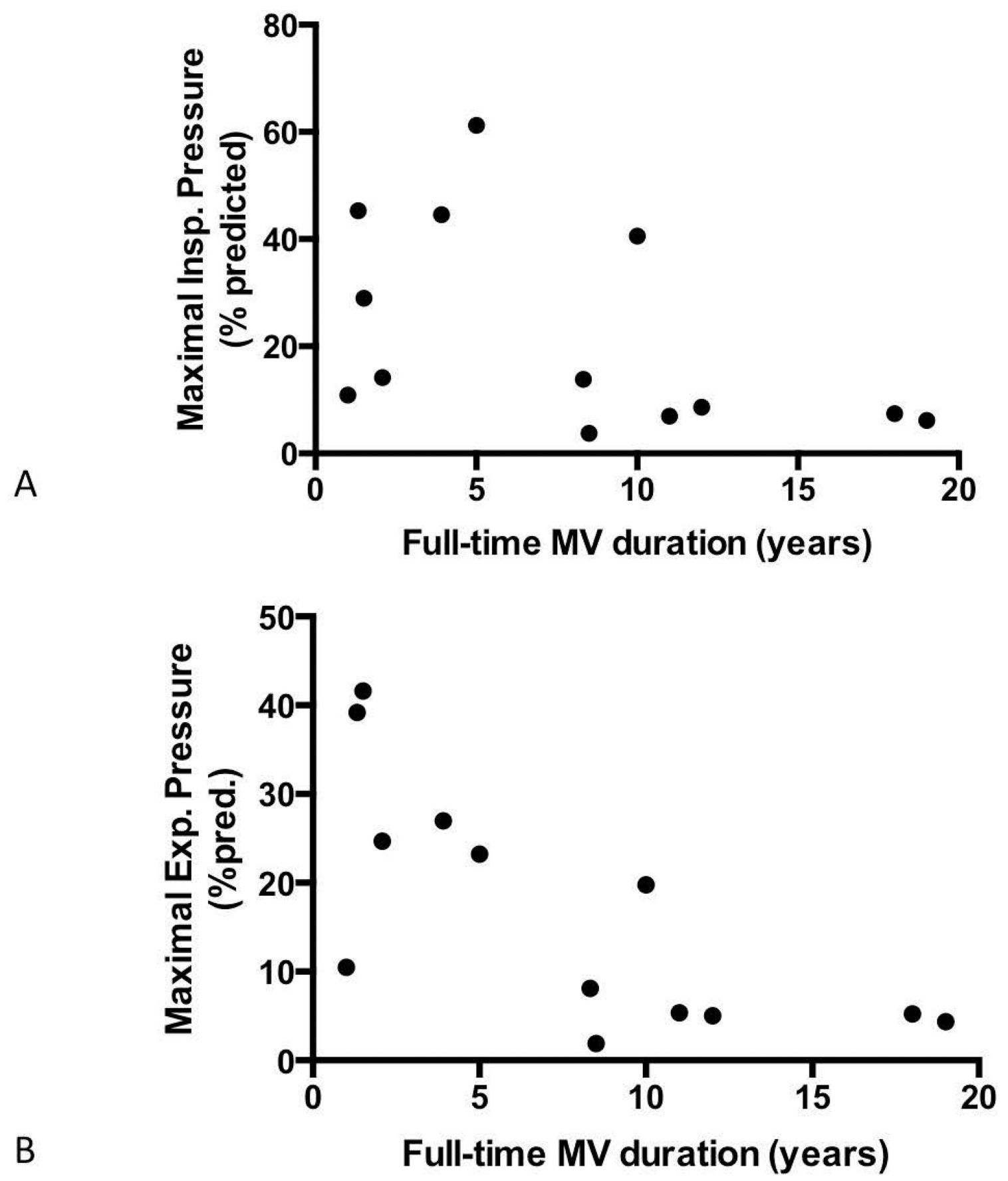

Figure 3.

Relationship between duration of invasive MV dependence and maximal respiratory pressures. (A) While predicted maximal inspiratory pressure was generally lower after prolonged periods of mechanical ventilation, it was not associated significantly with the duration of ventilator dependence $(\mathrm{r}=-0.482, P=0.10)$. (B) In contrast, duration was significantly associated with predicted maximal expiratory pressure $(\mathrm{r}=-0.715, P<0.01)$. 


\section{Table 2}

Breathing pattern on baseline mechanical ventilation and during unassisted breathing in patients with inflated, cuffed tracheostomies $(\mathrm{n}=8)$. Removal of respiratory support revealed a rapid, shallow breathing pattern and hypoventilation for most patients.

\begin{tabular}{lccc}
\hline Respiratory measure & Assisted & Unassisted & $\boldsymbol{P}$ \\
\hline Respiratory rate (breaths/minute) & $24 \pm 9$ & $36 \pm 7$ & $<0.01^{*}$ \\
Inspiratory time (seconds) & $1.02 \pm 0.24$ & $0.78 \pm 0.24$ & 0.10 \\
Expiratory time (seconds) & $1.49 \pm 0.56$ & $1.05 \pm 0.20$ & 0.07 \\
Tidal volume (mL) & $272 \pm 127$ & $74 \pm 35$ & $<0.005^{*}$ \\
Tidal volume (mL/kg) & $9.5 \pm 2.0$ & $3.3 \pm 2.7$ & $<0.005^{*}$ \\
Minute ventilation (L/min) & $5.6 \pm 1.7$ & $2.7 \pm 1.3$ & $<0.01^{*}$ \\
\hline
\end{tabular}

Reached statistical significance 